\title{
Rapid implementation of virtual neurology in response to the COVID-19 pandemic
}

Scott N. Grossman, MD, Steve C. Han, MD, Laura J. Balcer, MD, MSCE, Arielle Kurzweil, MD, Harold Weinberg, MD, PhD, Steven L. Galetta, MD, and Neil A. Busis, MD

Neurology ${ }^{\circledR}$ 2020;94:1077-1087. doi:10.1212/WNL.0000000000009677

\begin{abstract}
The COVID-19 pandemic is causing world-wide social dislocation, operational and economic dysfunction, and high rates of morbidity and mortality. Medical practices are responding by developing, disseminating, and implementing unprecedented changes in health care delivery. Telemedicine has rapidly moved to the frontline of clinical practice due to the need for prevention and mitigation strategies; these have been encouraged, facilitated, and enabled by changes in government rules and regulations and payer-driven reimbursement policies. We describe our neurology department's situational transformation from in-person outpatient visits to a largely virtual neurology practice in response to the COVID-19 pandemic. Two key factors enabled our rapid deployment of virtual encounters in neurology and its subspecialties. The first was a well-established robust information technology infrastructure supporting virtual urgent care services at our institution; this connected physicians directly to patients using both the physician's and the patient's own mobile devices. The second is the concept of one patient, one chart, facilitated by a suite of interconnected electronic medical record (EMR) applications on several different device types. We present our experience with conducting general teleneurology encounters using secure synchronous audio and video connections integrated with an EMR. This report also details how we perform virtual neurologic examinations that are clinically meaningful and how we document, code, and bill for these virtual services. Many of these processes can be used by other neurology providers, regardless of their specific practice model. We then discuss potential roles for teleneurology after the COVID-19 global pandemic has been contained.
\end{abstract}

\section{Correspondence}

Dr. Grossman

scott.grossman@

nyulangone.org

\section{MORE ONLINE}

\section{COVID-19 Resources}

For the latest articles, invited commentaries, and blogs from physicians around the world NPub.org/COVID19 


\section{Glossary}

CMS = Centers for Medicare and Medicaid Services; CPT = Current Procedural Terminology; $\mathbf{C N}=$ cranial nerve; EMR = electronic medical record; HHS $=$ Health and Human Services.

Clinical medicine in the United States has been transformed by the outbreak of the SARS-CoV-2, the virus that causes the syndrome of COVID-19. ${ }^{1}$ In December 2019, clusters of patients with pneumonia of unknown etiology were first identified. COVID-19 was declared a global pandemic on March 11, 2020. Since that time, the virus has spread rapidly, and, as of April 20, 2020, there were more than 750,000 confirmed cases in the United States and over 138,000 cases in New York City alone. ${ }^{2}$ Given the need for social isolation to help contain the spread of infection, neurology departments throughout the United States have turned to non-face-to-face visits as a means of providing patient care. ${ }^{3}$

Telemedicine can be defined as medical care provided to a patient by a physician or other health care provider at a different location. ${ }^{4}$ By the use of electronic communications technologies, it has the potential to overcome geographical, physical, and biological barriers to health care access, and it is safe, timely, efficient, and convenient. ${ }^{4-6}$ The adoption of telemedicine had been slowly progressing for the decades before the advent of COVID-19, with most telemedicine visits occurring for either primary or mental health care., ${ }^{7,8}$

Before the advent of COVID-19, impediments to the practice of telemedicine were considerable, including technological, political, regulatory, reimbursement, clinical, and social barriers. To ensure that patients in the United States have safe and timely access to health care during the coronavirus pandemic, the Department of Health and Human Services (HHS), the Centers for Medicare and Medicaid Services (CMS), and health care insurance companies loosened restrictive regulations and policies governing telemedicine. For the duration of this public health emergency, virtually all Current Procedural Terminology (CPT) codes for face-to-face outpatient, inpatient, critical care, and emergency department visits can now be used for virtual health visits. The major driver of telehealth adoption in the era of COVID-19 is the safety of all potential participants during a clinical encounter. Applicable safeguards include those for patients, family members, caregivers, and the health care teams.

New York University Langone Health (NYULH) was among the earliest health systems in the United States to be directly affected by COVID-19. Our system engaged in rapid efforts to prepare to care for large numbers of COVID-19 inpatients while simultaneously preserving a high standard of clinical excellence for other patients. Our neurologic outpatient care model transformed from purely in-person traditional office-based encounters to an almost universal system of direct-to-patient virtual visits.
With the intention of assisting other neurologists make similar adaptations, we describe our experience with the rapid transition to virtual neurology visits and offer recommendations for teleneurology examinations, appropriate coding, and potential implementation challenges.

\section{Concepts and background of virtual neurology visits}

Before the advent of widely available powerful mobile computing devices and broadband wireless network connectivity, teleneurology services were largely provided at health care facilities via dedicated telemedicine carts. ${ }^{4}$ Onsite telepresenters operated and supported the communication system and assisted the remote physician with examinations. Subsequent to the widespread adoption of smart phones and tablets with broadband networking capabilities, there has been movement toward virtual health care provided to patients using their personal devices at home. ${ }^{4,5,9}$

Our virtual urgent care system connects the provider directly to the patient using the patient's own mobile device or computer and network connection. ${ }^{10}$ The swift deployment of teleneurology services at NYU neurology leveraged the preexisting robust technology platforms developed for the NYU virtual urgent care system..$^{10}$ However, using this infrastructure required our teams to adapt the better-established more traditional teleneurology techniques to the newer direct-to-patient model. Another person co-located with the patient who can assist with the examination may enable a more effective neurologic evaluation in certain circumstances.

General terms such as telehealth or telemedicine do not fully convey the wide spectrum of services available with current electronic communication technologies. In this report, we focus on the implementation of synchronous real-time 2-way interactive audio and video visits.

No universal consensus yet exists that high-quality care for neurology patients can be achieved via virtual methods, but the evidence base is increasing. ${ }^{5,6}$ For instance, virtual stroke care is now well established. ${ }^{11-13}$ Recent reviews detailed the growing successes of teleneurology in caring for patients with neurologic disorders other than stroke.

\section{How we perform virtual neurology visits}

NYULH uses the Epic electronic medical record (EMR) ecosystem with interconnected apps on desktop and laptop 
computers, including Haiku on the iPhone and Canto on the iPad. Mobile devices are used by physicians for the virtual visits. Their front- and rear-facing device cameras are technologically superior to the single built-in cameras on desktop or laptop computers. The screen size on an iPhone is adequate for many clinical encounters, and the iPad screen is sufficient for detailed neurologic examinations. The ability to reposition the mobile device and to then switch from frontfacing to rear-facing cameras aids in demonstrating examination elements to the patient. The presence of an assistant in the patient's residence can add to the capacity to perform detailed and complete histories and examinations. Viewing the patient during a video visit on one device (mobile phone or tablet device) with Epic desktop open simultaneously on another (desktop or laptop computer) enables rapid medical record review and documentation without taking the focus off the patient. Two physicians can be logged in to the same virtual visit simultaneously, enabling supervision of trainees and providing real-time second opinions.

Virtual visits are integrated into the EMR, enabling each patient to have only one chart, regardless of visit type. This decreases administrative burden, eliminating duplicate data entry and reducing possible documentation errors. Patient schedules show a mixture of virtual and in-person visits. Check-in times to virtual waiting rooms and check-out times are logged. NYULH offers separate technical support lines for physicians and patients. For the best experience, specific instructions are sent to neurology patients to prepare in advance of the virtual visit.

The NYULH Department of Neurology has approximately 250 clinical faculty. All physicians who continued to see outpatients during the early period of COVID-19 participated in the transition to virtual visits. The financial effect of COVID-19 has been significant, with a reduction in visit volume at NYULH overall from approximately 30,000 to approximately 5,000 outpatients daily at present. Neurology outpatient volume at NYULH is approximately $50 \%$ of that observed before COVID-19.

\section{The virtual neurologic examination}

The essential elements of the in-person neurologic examination are well documented. ${ }^{14}$ How is it best to adapt the examination to a virtual visit? Several standardized neurologic rating scales have been validated for teleneurology, but there is no currently validated examination for general teleneurology. ${ }^{5}$ Neurologists and our patients need teleneurology examinations that are sensitive, specific, and suitable for the range of conditions that we evaluate and manage.

Although only 2 of the 5 senses are supported with current technology, sight and sound can yield much information that is clinically useful. Conducting teleneurology visits may help clinicians sharpen their observational skills and examination techniques for all of the patients they care for, whether inperson or virtually. Because virtual visits can support multiple participants in different locations, it may be easier in the context of a virtual visit to coordinate interviews with family members or with other knowledgeable observers in real time.

How to optimize and validate a teleneurology examination has been explored since at least the late 1990s. At that time, an early study compared face-to-face examinations performed by junior physicians with telemedicine examinations conducted by senior neurology trainees who observed the junior trainees. ${ }^{15}$ In that study, the gold standard was defined as an inperson examination by a senior neurologist. Investigators found that the telemedicine examination was more sensitive in detecting abnormalities than a face-to-face examination for all components; the telemedicine examination was more specific for all but one clinical sign (plantar response). ${ }^{15}$ However, most studies included trained presenters at the patient's location who could assist in performing the examination. $^{4-6}$ Teleneurology examinations have also been studied with different comparator models, including inperson home visits. ${ }^{5,16}$

Given the speed with which we needed to transition to virtual care during the COVID-19 pandemic, our teleneurology examination was designed by consensus, with plans for future research to identify and validate the essential elements of a clinically meaningful, useful, and reproducible teleneurology examination.

Some NYU neurology department faculty are more comfortable with virtual visits on established patients because there were previous face-to-face examinations for those individuals. We recognize that some virtual examination elements can be performed if the patient is alone, whereas others require another person in the home to assist. Some elements, such as a detailed funduscopic examination, cannot be performed remotely in direct-to-patient encounters. If the neurologist does not think that the virtual encounter is adequate to fully assess the patient, an in-person visit, when it is safe for the patient and provider to have such an encounter, will be recommended.

During this period of social distancing amid the COVID-19 pandemic, patients cannot have others help them unless they are socially isolating together. After social distancing policies are rescinded, we anticipate recommending that someone be present with the patient for many virtual visits.

The patient or an assistant are the camera operators, directors, producers, and technical support personnel for the visit. Mobile devices are preferred because their cameras are superior to desktop and laptop cameras, as the patient can also use the front-facing or rear-facing cameras of the device, and the device can be moved as needed to visualize examination elements. 
Patients may be asked to bring certain objects to their virtual appointment including the following:

- A stand for their mobile device or a selfie stick.

- A blood pressure cuff, if available, a scale, graph paper or Amsler grid (can be printed from internet search), something to read, a penlight/flashlight, a pen, a rubber band, a paper clip, a hand weight, a can, a milk carton or something similar, a tissue, cotton swab (Q-tip), toothpick, an ice cube in a plastic bag or other cold object such as a cold metal spoon, a kitchen spatula, and keys.

The patient may also be asked to download apps onto their mobile device.

A full neurologic examination, adapted to a direct-to-patient audio/video encounter, is shown in table 1. Certain aspects of the neurologic examination merit further discussion. The mental status examination has been reliably administered via telemedicine using the Mini-Mental State Examination and the Montreal Cognitive Assessment. ${ }^{17,18}$ Much of the cranial nerve $(\mathrm{CN})$ examination can be performed reliably via telemedicine through a combination of direct maneuvers and application-based supplements. The Eye Handbook application accurately measures visual acuity and color vision and has other examination features targeting CNs II, III, IV, and VI. ${ }^{19}$ Ophthalmoscopy of the optic discs is currently a major limitation of the virtual examination and cannot be performed in a typical virtual visit. However, strategies for remote capture of fundus photography are in development. Pupils can be examined by asking the patient to rapidly close and open the eyes or asking an assistant or the patient to approximate the swinging flashlight test. Ocular alignment poses a challenge for the remote examiner, but additional smartphone applications are in development to use automated Hirschberg testing to measure alignment patterns. ${ }^{20}$ Screenshots of ocular alignment can be captured and transferred to the EMR. These can reliably track broad alignment patterns or lid position.

There are limited data in the literature on how to best determine motor and sensory function of the trunk and limbs during a virtual examination. However, crowdsourcing produced some potentially productive techniques. Muscle strength can be tested by inspection, movement against gravity, quantified with weights or resistive objects, by an assistant, if present, or by functional activities such as the ability to stand from a seated position with or without the assistance of the upper extremities (table 1). The subtleties of deep tendon reflexes may be challenging to discriminate via telemedicine; however, an assistant, if present, can be instructed on how to perform a gross assessment of brisk or reduced reflexes and reflex asymmetry may be examined by tapping with an object or with fingers. Plantar reflexes can also be tested by the patient or assistant. Sensation can be tested by using the patient or an assistant's fingertips or with specific stimuli such as a cotton wisp, toothpick, or a cold metal object. Gait and station can be evaluated including toe, heel, and tandem walking, Romberg maneuver, and tandem Romberg maneuver. The practitioner should remind the patient without a nearby assistant to perform gait and station testing near a wall or stable object that they can use for support should they lose their balance.

The remote neurologic examination requires adaptation, ingenuity, and resourcefulness. The need for social distancing while still caring for patients with neurologic disorders incentivizes us to develop, refine, study, and validate clinically meaningful teleneurology examination techniques. We expect improvements as the teleneurology community grows and shares knowledge.

\section{Coding for virtual neurology encounters}

We realize that coding for visits is specific for the United States, but it remains a source of confusion and warrants discussion. Shortly before this article was written, the CMS and other payers dramatically loosened constraints on reimbursable telehealth services. Synchronous video and audio telemedicine services can now be used to evaluate new patients in addition to established patients. Patients can be examined in their homes. State medical licensing policies are still variable and constantly changing. Nonetheless, in many states, licensing rules are less exclusionary than they were before the global pandemic. Communications technologies used for telehealth need not be Health Insurance Portability and Accountability Act compliant for now. ${ }^{21}$

There are several non-face-to-face evaluation and management (E/M) services with corresponding CPT codes (table 2). Synchronous telemedicine encounters delivered through realtime interactive audio and video telecommunication systems closely resemble in-person E/M encounters, with documentation requirements to determine the level of service similar to standard face-to-face visits. Although the examination is limited in non-face-to-face evaluations, history, medical decision making, and determination of time of the service are not affected in major ways. The codes for these telemedicine E/M services are the same as for the corresponding face-to-face encounters with addition of a -95 or $-\mathrm{GT}$ modifier as determined by the payer.

Attestation and consent statements are added to teleneurology notes, but there are no universally accepted formats. They are organization and payer specific.

There are also telephone E/M codes 99441-99443, virtual check-in services G2012 and G2010, and online digital E/M codes 99421-99423 (table 2). Details on how to use them properly are available elsewhere. ${ }^{21-24}$

Major regulatory changes made by the CMS may or may not be adopted by other insurance payers. Each organization should frequently check with their panel of insurers to keep up to date on these rapidly changing policies. 
Table 1 Neurology examination adapted to direct-to-patient virtual encounters

1. General appearance of the patient (e.g., development, nutrition, body habitus, deformities, and attention to grooming)

On inspection via the video/audio connection.

2. Vital signs: measurement of any 3 of the following 7 (which may be measured and recorded by ancillary staff): sitting or standing blood pressure, supine blood pressure, pulse rate and regularity, respiration, temperature, height, and weight

Patient-supplied devices can get BP, pulse, weight easily, and also temperature if relevant.

3. Cardiovascular:

a. Examination of carotid arteries (e.g., pulse amplitude and bruits)

b. Auscultation of the heart with notation of abnormal sounds and murmurs

c. Examination of the peripheral vascular system by observation (e.g., swelling and varicosities) and palpation (e.g., pulses, temperature, edema, and tenderness)

Probably unable to be assessed unless an assistant who is a medical professional is present

4. Attention span and concentration

Via the video/audio connection.

5. Orientation to person, place, and time

Via the video/audio connection.

6. Language (e.g., naming objects, repeating phrases, and spontaneous speech)

Via the video/audio connection.

7. Fund of knowledge (e.g., awareness of current events, past history, and vocabulary)

Via the video/audio connection.

8. Recent and remote memory

Via the video/audio connection.

Additional tools for more detailed mental status assessment:

MOCA appropriate for telemedicine. ${ }^{18}$ mocatest.org/remote-moca-testing/

$\mathrm{MMSE}^{17}$

9. 2nd cranial nerve (e.g., visual acuity, visual fields, and fundi)

Confrontation visual fields performed by the examiner on the computer screen for gross assessment. Ask the patient to report any blurring or absence of the examiner's facial features.

Home Amsler grid using a graph paper.

Reading.

When appropriate: Eye Handbook App for acuity and color vision. ${ }^{19}$ The download is free.

10. Ophthalmoscopic examination of optic discs (e.g., size, cup to disc ratio, and appearance) and posterior segments (e.g., vessel changes, exudates, and hemorrhages)

Not possible unless there is a tele-ophthalmoscope.

Fundus photographs can be submitted, but they would be considered data reviewed, not an examination element.

11. 3rd, 4th, and 6th cranial nerves (e.g., pupils and eye movements)

Open and close eyes to look for pupillary reaction to ambient light, or use penlight/flashlight, patient or home assistant may be able to do swinging flashlight test.

Ask the patient to look left, right, up, and down with head still.

Sustained upgaze for 30-60 seconds.

Optokinetic nystagmus feature of Eye Handbook App may help assess pursuit and saccades, a home assistant may help with smooth pursuit testing

Convergence testing using the thumb of patient slowly brought to their nose.

Vestibulo-ocular reflex testing by having them look at the camera and quickly turn their head to the sides. 
Table 1 Neurology examination adapted to direct-to-patient virtual encounters (continued)

12. 5th cranial nerve (e.g., facial sensation and corneal reflexes)

Touch with tissue and cotton swab (Q-tip).

Temperature with cold object.

Sharp with toothpick or other object.

13. 7th cranial nerve (e.g., facial symmetry and strength)

Inspection via the video/audio connection for facial symmetry, smiling, and nasolabial fold flattening.

NIHSS item 4.

Specific movements:

Raising eyebrows.

Eye closure.

Ability to wink on either side.

Ability to completely bury the eyelashes on forceful eye closure.

Peek sign. ${ }^{33}$

Pucker lips.

Whistle.

14. 8th cranial nerve (e.g., hearing with tuning fork, whispered voice, and/or finger rub)

Via the video/audio connection-can they hear the examiner?

Finger rub in either ear by the patient or assistant.

Balance maneuvers with tandem Romberg.

Home Epley has been performed with detailed patient instructions.

15. 9th cranial nerve (e.g., spontaneous or reflex palate movement)

Probably best with assistant and penlight/flashlight, holding the camera very close to opened mouth to inspect palatal movement.

Instruct the patient to swallow while you watch the Adam's apple to see whether it moves up and down.

16. 11th cranial nerve (e.g., shoulder shrug strength)

Inspect movement via the video/audio connection.

17. 12th cranial nerve (e.g., tongue protrusion)

Ability to protrude the tongue.

Ability to move tongue rapidly side to side.

Ability to click the tongue.

Look for atrophy or fasciculations.

Speech/dysarthria (many cranial nerves):

Listening and watching via the video/audio connection.

Counting aloud from 1 to 50 .

18. Muscle strength in upper and lower extremities

Inspection via the video/audio connection for gross movements, posturing, movements against gravity, symmetry of movement, and drift of the arms or legs.

NIHSS items 5 and 6 .

Quantitative with weights.

Exercises-push-ups, stand up from the floor, stand up from the chair without using arms, going up and down steps, walk on heels, and walk on toes. 
Table 1 Neurology examination adapted to direct-to-patient virtual encounters (continued)

Assistant to perform confrontation testing if possible (e.g., pushing/pulling against resistance).

Neck strength:

Ability to touch the chin to the chest when lying supine.

Specific upper limb testing:

Ability to raise the arms above one's head

Lifting objects of different weights.

Sustained abduction of the arms for up to 120 seconds.

Ability to blanch the knuckles when making a fist.

Ability to completely bury the distal phalanx when making a fist.

Ability to spread rubber band using one's fingers (tests finger abduction).

Holding a paper clip or pen between the fingers (tests finger adduction).

Placing a paper clip on a paper.

O-sign using the first and second fingers.

Ability to snap fingers.

Ability to cross fingers.

Handwriting.

Specific lower limb testing:

Repeated arising from a chair without the use of the arms, up to 20 reps.

Ability to arise from a squat or from the floor.

Ability to step up on a low chair with 1 leg.

Ability to stand on each leg.

Ability to hop on each leg.

Straight leg sustained elevation while lying supine, up to 90 seconds.

Ability to spread toes.

Ability to flex toes and cup the soles of the feet.

19. Muscle tone in upper and lower extremities (e.g., flaccid, cogwheel, and spastic) with notation of any atrophy or abnormal movements (e.g., fasciculation and tardive dyskinesia)

Shaking hands/arms while standing to observe for flail arms.

Shaking of the legs in supine and sitting dangling over the edge of the bed.

Bradykinesia, tremors, and involuntary movements via the video/audio connection.

Bulk: inspection by video close-up or images obtained at the time of examination or by the patient to be imported into the EMR if indicated.

20. Coordination (e.g., finger/nose, heel/knee/shin, rapid alternating movements in the upper and lower extremities, and evaluation of fine motor coordination in young children)

Inspection via the video/audio connection.

Finger-nose.

Heel-knee-shin

NIHSS item 7.

Rapid alternating movements of upper limbs:

Tapping the thumb and index finger

Turning hands in alternating movements. 
Table 1 Neurology examination adapted to direct-to-patient virtual encounters (continued)

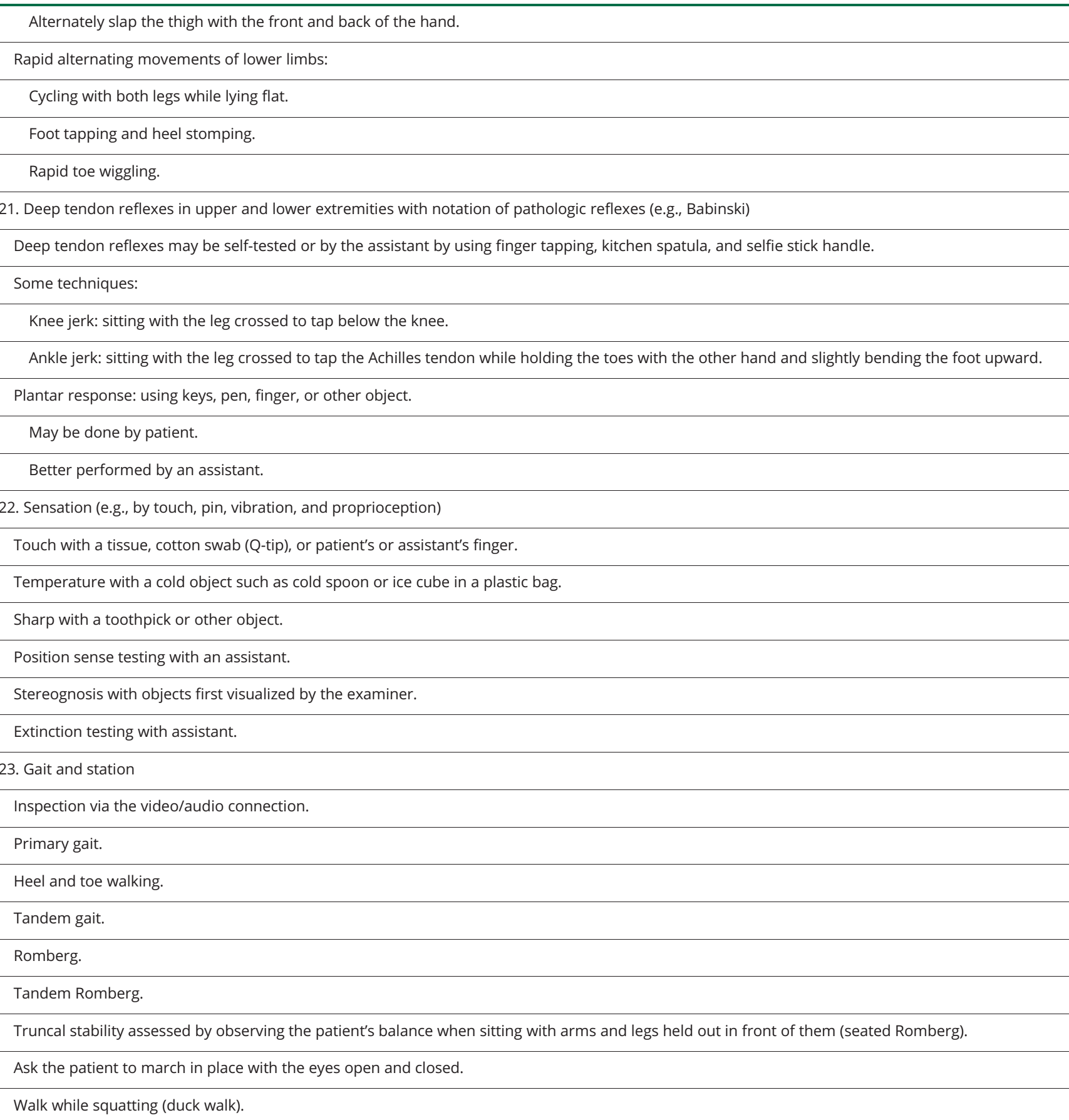

Abbreviations: $\mathrm{EMR}$ = electronic medical record; MMSE = Mini-Mental State Examination; MoCA = Montreal Cognitive Assessment; NIHSS = National Institutes of Health Stroke Scale.

\section{Challenges to successful implementation of a virtual neurology program}

Our major challenges revolve around patients, communications technology, changes in practice patterns and policies, rules, and regulations. They are likely to be independent of our specific practice model or EMR.
Examining patients remotely requires cooperation and mutual awareness, with explicit directions to patients and family members. The use of family members in examination, while at times necessary, can contribute to feelings of inadequacy and lack of control in patients. ${ }^{25}$

There is variability in patients' capacity to operate their mobile device even with maximal coaching. This can in terfere with the physician's ability to complete a visit in 
Table 2 Summary of non-face-to-face services, corresponding codes, and descriptions

\begin{tabular}{|c|c|c|}
\hline Service type & Code & Description \\
\hline $\begin{array}{l}\text { Synchronous Telemedicine Services Rendered via } \\
\text { a Real-Time Interactive Audio and Video } \\
\text { Telecommunications System }\end{array}$ & $\begin{array}{l}\text { Use appropriate face-to- } \\
\text { face E/M codes with } \\
\text { modifier -95 or -GT }\end{array}$ & $\begin{array}{l}\text { These codes are the same as face-to-face visits reported with } \\
\text { a modifier to designate the service as a telemedicine encounter. }\end{array}$ \\
\hline \multirow[t]{3}{*}{ Telephone E/M Services } & 99441 & $\begin{array}{l}\text { Telephone evaluation and management service by a physician or } \\
\text { other qualified health care professional who may report } \\
\text { evaluation and management services provided to an established } \\
\text { patient, parent, or guardian not originating from a related E/M } \\
\text { service provided within the previous } 7 \mathrm{~d} \text { nor leading to an E/M } \\
\text { service or procedure within the next } 24 \mathrm{~h} \text { or soonest available } \\
\text { appointment; 5-10 min of medical discussion }\end{array}$ \\
\hline & 99442 & 11-20 min of medical discussion \\
\hline & 99443 & 21-30 min of medical discussion \\
\hline Virtual Check-Ins & G2010 & $\begin{array}{l}\text { Remote evaluation of recorded video and/or images submitted by } \\
\text { an established patient (e.g., store and forward), including } \\
\text { interpretation with follow-up with the patient within } 24 \text { business } \\
\text { hours, not originating from a related E/M service provided within } \\
\text { the previous } 7 \mathrm{~d} \text { nor leading to an E/M service or procedure within } \\
\text { the next } 24 \mathrm{~h} \text { or soonest available appointment }\end{array}$ \\
\hline
\end{tabular}
in, by a physician or other qualified health care professional who can report evaluation and management services, provided to an established patient, not originating from a related E/M service provided within the previous $7 \mathrm{~d}$ nor leading to an E/M service or procedure within the next $24 \mathrm{~h}$ or soonest available appointment; 5-10 min of medical discussion

\begin{tabular}{lll}
\hline Online Digital E/M Services & 99421 & $\begin{array}{l}\text { Online digital evaluation and management service, for an } \\
\text { established patient, for up to } 7 \mathrm{~d} \text {, cumulative time during the } 7 \mathrm{~d} \text {; } \\
5-10 \mathrm{~min}\end{array}$ \\
\hline 99422 & $11-20 \mathrm{~min}$ \\
\hline 99423 & 21 or more minutes \\
\hline
\end{tabular}

CPT Copyright 2019 American Medical Association. All rights reserved.

CPT is a registered trademark of the American Medical Association.

a timely manner. Limitations in patients' abilities to print examination materials have also detracted from examination quality.

Patients with cognitive, visual, or hearing impairments who do not have suitable assistants may also be impeded from having effective direct-to-patient telehealth encounters. However, at NYULH, the cognitive neurology division noted that approximately $80 \%$ of patients and their families have been able to successfully complete a virtual visit.

Socioeconomic determinants of health can adversely affect access to telehealth. Some patients do not have access to appropriate computing devices or network connections and may not have a location that is large enough for full assessment of neurologic function or secluded enough to perform the examination with adequate privacy.

The physical environment of the physician's office, regardless of location, should be adapted to optimize the virtual encounter. Using a stand or holder for the mobile device helped ensure a good virtual encounter experience for many physicians. Having an area to conduct telehealth encounters devoid of visual or auditory distractions, which improves the patient experience and helps protect patient information, has been a challenge for some. Mobile device battery life is sometimes a limiting factor.

Workflow does not yet fully accommodate virtual encounters. After the virtual visit concludes, there is no equivalent to inperson office staff to schedule follow-up appointments or studies. Clinicians must ensure that the care plan is not dropped or miscommunicated. In many in-person practices, patients complete forms before in-person visits that list medications, allergies, past medical, family, and social history, and review of systems. We have not yet developed versions of these forms for virtual visits.

Transitioning the faculty practice to virtual visits has been quite challenging. All physicians had full in-person visit schedules for several months into the future before the onset of COVID-19. There was a considerable administrative burden converting as many in-person visits as possible to virtual visits, especially because some patients were resistant to the 
proposed switch. We anticipate that the burden will lessen with time as physicians, staff, and patients become accustomed to the new care model.

Some of the greatest challenges cited by physicians in the department include limitations of specific examination maneuvers that require onsite assistance or special equipment. Technologies to deploy nonmydriatic fundus photography in the emergency department are currently being investigated, but these approaches are more challenging to deploy in the direct-to-patient video visit care model. ${ }^{26} \mathrm{We}$ hope that devices attached to the iPhone will become easier for family members and others to use.

The new rules, regulations, and policies in response to the global pandemic from government agencies and other policy makers and payers have been necessary, but not sufficient, to enable the rapid introduction of virtual healthcare services. They are constantly changing. We need to keep up to date on all relevant rules and regulations, inform the appropriate stakeholders, and implement them in our system.

\section{Future opportunities}

This article focused on synchronous telemedicine encounters delivered through real-time interactive audio and video telecommunication systems. What will be the roles of teleneurology encounters after the COVID-19 pandemic has been controlled? There are other virtual technologies, including asynchronous ones, which were not discussed, that can potentially be used to improve neurologic patient care. The shift to large numbers of virtual visits affords new opportunities to study teleneurology that should help answer these and related questions. ${ }^{27}$

Will patient and physician expectations be met with regard to diagnostic accuracy without corroboration with an in-person visit? If so, for which neurologic conditions? How can specialized neurologic examination techniques, such as fundus photography in neuro-ophthalmology or head-impulse testing in neuro-otology, be incorporated into virtual visits?

We anticipate that evidence will demonstrate that virtual visits are valuable in certain clinical contexts and will augment inperson visits for many types of non-stroke neurology patients, just as evidence has supported integration of telestroke into mainstream stroke care.

Certain telehealth technologies may be incorporated into inperson visits. For example, physicians can digitally capture aspects of the physical examination, which are currently only documented in a written note, such as images of eye movements in different gaze positions and the appearance of a patient's tremor. ${ }^{28}$

Will payers continue to cover telehealth services and at what rates after the global pandemic is controlled? Regulators and payers may encourage integration of telemedicine services into mainstream clinical practice by reimbursing them appropriately. Their decision may depend not only on evidence of efficacy and validity but on societal acceptance, the desire of patients and medical practitioners to continue practicing virtually. Standardization of state laws and attestation and consent statements and coding and billing practices would further facilitate implementation of teleneurology.

If there is widespread acceptance of telehealth, will it spur further consolidation of medical practices? Will more telehealth availability lead to overutilization? What are the implications for medical liability? What about medical and postgraduate medical education?

Conceptually, clinicians and patients can interact within telemedicine through many different channels. ${ }^{29}$ Desruisseaux et al. ${ }^{29}$ proposed that each channel of interaction has 2 relevant outcomes: savings, defined as the financial difference in money and time between traditional care models and each channel, and resolution, defined as an encounter that meets the standard of care and gives the patient a good experience. Maximizing these outcomes requires efficiently and precisely funneling each interaction into the appropriate channel. Health systems are only now beginning to grasp the importance of this process. ${ }^{29}$ If such implementation is successful, improvements in financial and care-related performance could be significant. ${ }^{30,31}$

As we advance teleneurology, we must be mindful of the effect of telehealth on the physician-patient relationship and the potential for widening health disparities.

Teleneurology may be the gateway to incorporating machine learning techniques and artificial intelligence into neurologic care. $^{28,32}$ Once audio and visual clinical data are available in electronic form, advanced computing technologies can be used to transform this unstructured data into the structured data needed for medical decision making. ${ }^{28}$

\section{Study funding}

No targeted funding reported.

\section{Disclosure}

S.N. Grossman, S.C. Han, L.J. Balcer, A. Kurzweil, H. Weinberg, and S.L. Galetta report no relevant disclosures. N.A. Busis receives honoraria for speaking at American Academy of Neurology courses and for serving as Alternate CPT Advisor for the American Academy of Neurology and is a former member of the American Academy of Neurology Board of Directors. Go to Neurology.org/N for full disclosures.

\section{Publication history}

Received by Neurology April 8, 2020. Accepted in final form April 22, 2020. 
Appendix Authors

\begin{tabular}{lll}
\hline Name & Location & Contribution \\
\hline $\begin{array}{l}\text { Scott N. } \\
\text { Grossman, } \\
\text { MD }\end{array}$ & $\begin{array}{l}\text { New York University } \\
\text { Grossman School of } \\
\text { Medicine, New York, NY }\end{array}$ & $\begin{array}{l}\text { Designed and } \\
\text { conceptualized the study } \\
\text { and drafted the manuscript } \\
\text { for intellectual content }\end{array}$ \\
\hline $\begin{array}{l}\text { Steve C. } \\
\text { Han, MD }\end{array}$ & $\begin{array}{l}\text { New York University } \\
\text { Grossman School of } \\
\text { Medicine, New York, NY }\end{array}$ & $\begin{array}{l}\text { Drafted the manuscript for } \\
\text { intellectual content }\end{array}$ \\
\hline $\begin{array}{l}\text { Laura J. } \\
\text { Balcer, MD, } \\
\text { MSCE }\end{array}$ & $\begin{array}{l}\text { New York University } \\
\text { Grossman School of }\end{array}$ & $\begin{array}{l}\text { Drafted the manuscript for } \\
\text { intellectual content }\end{array}$ \\
\hline $\begin{array}{l}\text { Arielle } \\
\text { Kurzweil, } \\
\text { MD }\end{array}$ & $\begin{array}{l}\text { New York University } \\
\text { Grossman School of } \\
\text { Medicine, New York, NY }\end{array}$ & $\begin{array}{l}\text { Drafted the manuscript for } \\
\text { intellectual content }\end{array}$ \\
\hline $\begin{array}{l}\text { Harold } \\
\text { Weinberg, } \\
\text { MD, PhD }\end{array}$ & $\begin{array}{l}\text { New York University } \\
\text { Grossman School of } \\
\text { Medicine, New York, NY }\end{array}$ & $\begin{array}{l}\text { Designed and } \\
\text { conceptualized the study } \\
\text { and drafted the manuscript } \\
\text { for intellectual content }\end{array}$ \\
\hline $\begin{array}{l}\text { Steven L. } \\
\text { Galetta, } \\
\text { MD }\end{array}$ & $\begin{array}{l}\text { New York University } \\
\text { Grossman School of } \\
\text { Medicine, New York, NY }\end{array}$ & $\begin{array}{l}\text { Designed and } \\
\text { conceptualized the study } \\
\text { and drafted the manuscript } \\
\text { for intellectual content }\end{array}$ \\
\hline $\begin{array}{l}\text { Neil A. } \\
\text { Busis, MD }\end{array}$ & $\begin{array}{l}\text { New York University } \\
\text { Grossman School of } \\
\text { Medicine, New York, NY }\end{array}$ & $\begin{array}{l}\text { Designed and } \\
\text { conceptualized the study } \\
\text { and drafted the manuscript } \\
\text { for intellectual content }\end{array}$ \\
\hline & &
\end{tabular}

\section{References}

1. Zhu N, Zhang D, Wang W, et al. China novel coronavirus investigating and research team. A novel coronavirus from patients with pneumonia in China, 2019. N Engl J Med 2020;382:727-733.

2. Dong E, Du H, Gardner L. An interactive web-based dashboard to track COVID-19 in real time. Lancet Infect Dis 2020 May;20:533-534.

3. Centers for Disease Control and Prevention. Public health recommendations for community-related exposure. Available at: cdc.gov/coronavirus/2019-ncov/php/ public-health-recommendations.html. Accessed April 20, 2020.

4. Wechsler LR. Advantages and limitations of teleneurology. JAMA Neurol 2015;72: 349-354.

5. Dorsey ER, Glidden AM, Holloway MR, Birbeck GL, Schwamm LH. Teleneurology and mobile technologies: the future of neurological care. Nat Rev Neurol 2018;14: 285-297.

6. Hatcher-Martin JM, Adams JL, Anderson ER, et al. Telemedicine in neurology: telemedicine work group of the American Academy of neurology update. Neurology 2020;94:30-38.

7. Barnett ML, Ray KN, Souza J, Mehrotra A. Trends in telemedicine use in a large commercially insured population, 2005-2017. JAMA 2018;320:2147-2149.

8. Duffy S, Lee TH. In-person health care as option B. N Engl J Med 2018;378:104-106
9. Adams JL, Tarolli CG, Dorsey ER. Next generation house call. Cerebrum 2017 Jan 1; 2017. pii: cer-02-17.

10. Mann DM, Chen J, Chunara R, Testa PA, Nov O. COVID-19 transforms health care through telemedicine: evidence from the field. J Am Med Inform Assoc Epub 2020 Apr 23

11. Guzik AK, Switzer JA. Teleneurology is neurology. Neurology 2020;94:16-17.

12. Kepplinger J, Barlinn K, Deckert S, Scheibe M, Bodechtel U, Schmitt J. Safety and efficacy of thrombolysis in telestroke: a systematic review and meta-analysis. Neurology 2016;87:1344-1351.

13. Sharma R, Zachrison KS, Viswanathan A et al. Trends in telestroke care delivery: a 15year experience of an academic hub and its network of spokes. Circ Cardiovasc Qual Outcomes 2020;13:e005903.

14. Campbell WW, Barohn RJ. DeJong's the Neurologic Examination, 8th ed. Philadelphia: Wolters Kluwer; 2020.

15. Craig JJ, McConville JP, Patterson VH, Wootton R. Neurological examination is possible using telemedicine. J Telemed Telecare 1999;5:177-181.

16. Chua R, Craig J, Wootton R, Patterson V. Randomised controlled trial of telemedicine for new neurological outpatient referrals. J Neurol Neurosurg Psychiatry 2001;71: 63-66.

17. McEachern W, Kirk A, Morgan DG, Crossley M, Henry C. Reliability of the MMSE administered in-person and by telehealth. Can J Neurol Sci 2008;35:643-646.

18. Chapman JE, Cadilhac DA, Gardner B, Ponsford J, Bhalla R, Stolwyk RJ. Comparing face-to-face and videoconference completion of the Montreal Cognitive Assessment (MoCA) in community-based survivors of stroke. J Telemed Telecare Epub 2019 Dec 19.

19. Lord K, Shah VA, Krishna R. The Eye Handbook: a mobile app in ophthalmic medicine. Mo Med 2013;110:49-51.

20. Pundlik S, Tomasi M, Liu R, Houston K, Luo G. Development and preliminary evaluation of a smartphone app for measuring eye alignment. Transl Vis Sci Technol 2019;8:19.

21. Cohen BH, Busis NA, Ciccarelli L. Coding in the world of COVID-19: non-face-toface evaluation and management care. Continuum: lifelong learning in Neurology. Available at: cdn-links.lww.com/permalink/cont/a/cont_2020_03_26_coding 2020-19_sdc3.pdf. Accessed April 20, 2020

22. American Medical Association. CPT 2020. Professional Edition. Chicago: American Medical Association; 2019

23. Centers for Medicare and Medicaid Services. Available at: cms.gov/. Accessed April 20, 2020

24. American Academy of Neurology. COVID-19 Neurology Resource Center. 2020; Available at: aan.com/tools-and-resources/covid-19-neurology-resource-center/. Accessed April 20, 2020.

25. Seuren LM, Wherton J, Greenhalgh T, Cameron D, A'Court C, Shaw SE. Physical examinations via video for patients with heart failure: qualitative study using conversation analysis. J Med Internet Res 2020;22:e16694.

26. Biousse V, Bruce BB, Newman NJ. Ophthalmoscopy in the 21st century: the $2017 \mathrm{H}$. Houston merritt lecture. Neurology 2018;90:167-175.

27. Klein BC, Busis NA. COVID-19 is catalyzing the adoption of teleneurology. Neurology Epub 2020 Apr 1.

28. Kvedar JC. Evidence for the effectiveness of digital health. NPJ Digit Med 2020;3:34

29. Desruisseaux M, Stamenova V, Bhatia RS, Bhattacharyya O. Channel management in virtual care. NPJ Digit Med 2020;3:44.

30. Levine DM, Dixon RF, Linder JA. Association of structured virtual visits for hypertension follow-up in primary care with blood pressure control and use of clinical services. J Gen Intern Med 2018;33:1862-1867.

31. Hoonakker PLT, Carayon P, Cartmill RS. The impact of secure messaging on workflow in primary care: results of a multiple-case, multiple-method study. Int J Med Inform 2017;100:63-76

32. Milea D, Najjar RP, Zhubo J, et al. Artificial intelligence to detect papilledema from ocular fundus photographs. N Engl J Med 2020 Apr 30;382:1687-1695

33. Osher RH, Griggs RC. Orbicularis fatigue: the 'peek' sign of myasthenia gravis. Arch Ophthalmol 1979;97:677-679.

\section{AAN Online Learning}

Browse a variety of online CME, self-assessment, and other learning activities to suit your wide-ranging interests and learning styles. Visit AAN.com/Learn. 


\section{Neurology}

\section{Rapid implementation of virtual neurology in response to the COVID-19 pandemic}

Scott N. Grossman, Steve C. Han, Laura J. Balcer, et al.

Neurology 2020;94;1077-1087 Published Online before print May 1, 2020

DOI 10.1212/WNL.0000000000009677

\section{This information is current as of May 1, 2020}

\section{Updated Information \& Services}

References

Citations

Subspecialty Collections

Permissions \& Licensing

Reprints including high resolution figures, can be found at: http://n.neurology.org/content/94/24/1077.full

This article cites 21 articles, 4 of which you can access for free at: http://n.neurology.org/content/94/24/1077.full\#ref-list-1

This article has been cited by 5 HighWire-hosted articles: http://n.neurology.org/content/94/24/1077.full\#\#otherarticles

This article, along with others on similar topics, appears in the following collection(s):

\section{Clinical neurology examination}

http://n.neurology.org/cgi/collection/clinical_neurology_examination

\section{Coding}

http://n.neurology.org/cgi/collection/coding

Electronic medical records

http://n.neurology.org/cgi/collection/electronic_medical_records

Information about reproducing this article in parts (figures,tables) or in its entirety can be found online at:

http://www.neurology.org/about/about_the_journal\#permissions

Information about ordering reprints can be found online:

http://n.neurology.org/subscribers/advertise

Neurology ${ }^{\circledR}$ is the official journal of the American Academy of Neurology. Published continuously since 1951, it is now a weekly with 48 issues per year. Copyright (C 2020 American Academy of Neurology. All rights reserved. Print ISSN: 0028-3878. Online ISSN: 1526-632X.

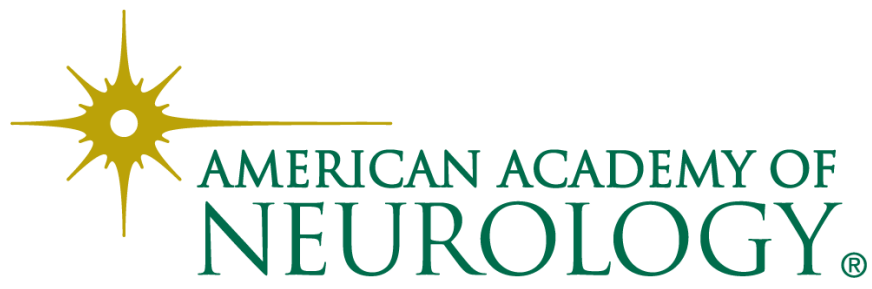

